\title{
EAl Endorsed Transactions

\section{Optimal Generation Dispatch of Ethiopian Power System Using Hybrid Genetic Algorithm-Hopfield Neural Network}

\author{
Shewit Tsegaye ${ }^{1 *}$ and Getachew Bekele ${ }^{2}$ \\ ${ }^{1}$ Jimma University (JU), 378, Jimma, Ethiopia \\ ${ }^{2}$ Addis Ababa University (AAU), 385, Addis Ababa, Ethiopia
}

\begin{abstract}
In this paper, an optimal generation dispatch of the Ethiopian power system using a hybrid Genetic Algorithm-Hopfield Neural Network (GA-HNN) is presented to reduce recursive blackouts. Reformulation of generation dispatch for a power grid comprising biomass, hydro, solar, waste to energy plant, wind and geothermal have been carried out. Each of these sources requires a mathematical formulation that considers security limits and intermittency of renewables. Modelling and simulation was conducted on MATLAB. According to the simulation results obtained, it can be deduced that GA-HNN based optimal generation dispatch of Ethiopian power system is a key solution in connection to developments needed in the adoption and realization of smarter grids as it concurrently increases its security level and decreases total generation cost. Generally, reducing the number of recursive blackouts, decreasing generation cost, allocating optimal generation level, and reducing computation time are prospects of employing GA-HNN based OGD.
\end{abstract}

Keywords: Hopfield Neural Networks, Optimal Generation Dispatch, Genetic Algorithm, and Hybrid Hopfield Neural NetworkGenetic-Algorithm, Ethiopian Power system.

Received on 20 May 2021, accepted on 12 August 2021, published on 13 August 2021

Copyright (C) 2021 Shewit Tsegaye et al., licensed to EAI. This is an open access article distributed under the terms of the Creative Commons Attribution licence (http://creativecommons.org/licenses/by/3.0/), which permits unlimited use, distribution and reproduction in any medium so long as the original work is properly cited.

doi: 10.4108/eai.13-8-2021.170673 * Corresponding author. Shewit Tsegaye is with the faculty of electrical and computer engineering, Jimma University, Jimma, Ethiopia. Email:
tsegayshewit@yahoo.com, Phone: +251920427005.

\section{Introduction}

Sudden power outages can result in a highly regarded threat to the socio-economic endeavours of the community. Considering the Ethiopian power network, which is a power system of renewable energy sources, entertains recursive blackouts and frequent interruptions. An estimated $85 \%$ of customers participated in an interview say that these blackouts have devastating effect whenever it rains, during holidays and weekends. Consequently, these blackouts impose substantial damage on production plants, service centres, and home appliances [1].
According to [1] the Ethiopian power system from 2013 to 2016 reported 15 major blackouts. Production plants and service centres were down for an average of four months a year. Natural incidents, equipment failure, and power mismatch, collectively known as contingencies, caused these sudden interruptions and blackouts. A contingency is an event that removes one or more generators or transmission lines from the power system, increasing the stress on the remaining network [2] [3].

One of the main challenging aspects of power system operation is that electrical energy is difficult to store in significant amounts. This aspect requires a continuous balance between generation and demand that considers security constraints and contingencies. 
The other challenge is related to the integration of intermittent renewable energy sources [4] [5]. One of the daily power operation tasks that can coin these challenges is OGD [3] [6]. OGD is a process of allocating generation levels to generating units to economically supply the load while satisfying security constraints [7] [8]. Simply put, OGD means to economically order a generating unit to generate more or less power subject to operational constraints. The main objective of OGD is to minimize the power operation cost, while continuously respecting the operational constraints of the power system as illustrated in Figure 1.

Economic dispatch illustrative example: Power Demand $=200 \mathrm{MW}$

\begin{tabular}{|lll|}
\hline Generation Units & $\# 1$ & $\# 2$ \\
\hline Minimum generation (MW) & 50 & 0 \\
\hline Maximum generation (MW) & 200 & 100 \\
\hline Incremental cost (\$/MW) & 1 & 2 \\
\hline Lines & $\# 1$ & $\# 2$ \\
\hline Maximum flow & 100 & 120 \\
\hline
\end{tabular}

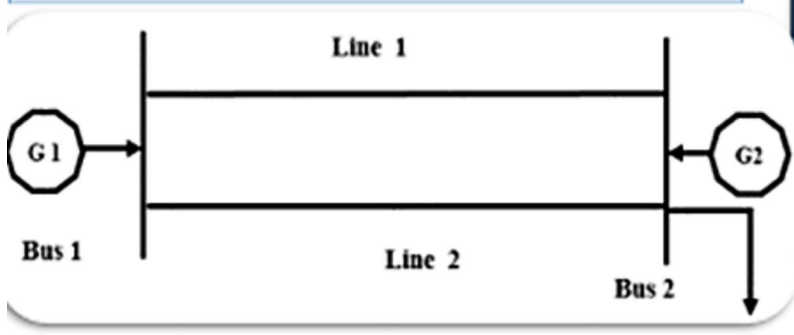

Since generator \#1 has the lowest operation cost and the only objective is to minimize the operation cost, the ideal economic dispatch would be :
Total cost $=200 \$$

Suppose now that OGD is

required. i.e.

the system

should have no

system

overload if

either of the

lines outages.

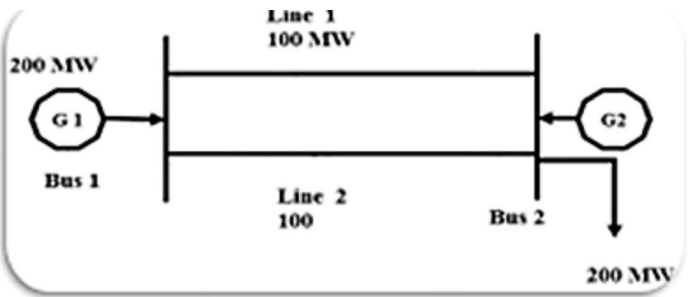

Output of generator $\# 1$

is constrained by the capacity of the

remaining line. Since

line\#1 has the lowest

capacity the most

severe contingency

corresponds to line\#2.

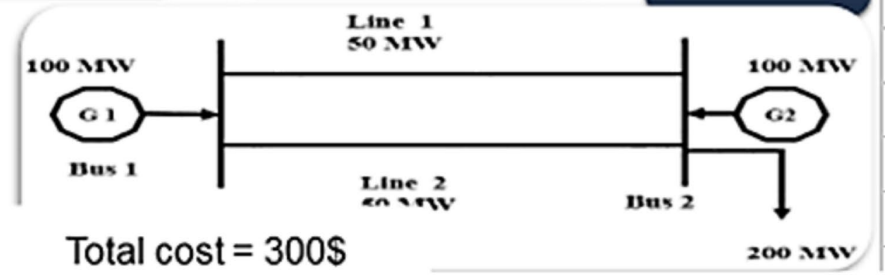

OGD requires higher operation cost than ideal economic dispatch because preventative generation at Bus 2 is required

Now suppose generators \#1 and \#2 require $40 \mathrm{MW}$ and $35 \mathrm{MW}$ ramping requirement for corrective measures, i.e. the high preventative cost must be reduced by some corrective actions

A better Economic dispatch for more constraints and three conflicting objective is thus : increasing emphasis on utilizing more renewables, (9]. Some methods chniques, interior point method, linear programming, nd dynamic programming [10] [11]. 
A bibliographic review reveals that OGD is an optimization problem that addresses over three conflicting objectives, which makes it a challenging computational problem [12]. Some methods have been used to solve this problem since its introduction, such as the iterative method, gradient-based techniques, interior point method, linear programming, and dynamic programming [13] [14]. A substantial number of articles reported OGD in the perspective of artificial intelligence [15] [16], renewable energy generation [17], and post-disturbance corrective actions [18] [19].
In this paper, it is put the choice firmly on:

- Formulating the OGD problem of the Ethiopian power system as separate objective functions.

- Predictive control of intermittent renewable generation and demand profiles using neural networks.

- Solving OGD of Ethiopian power system using a hybrid Genetic Algorithm-Hopfield Neural Network (GA-HNN) approach

Articulation of the challenging aspects of generation dispatch and intermittency of renewables is also the novelty of this study.

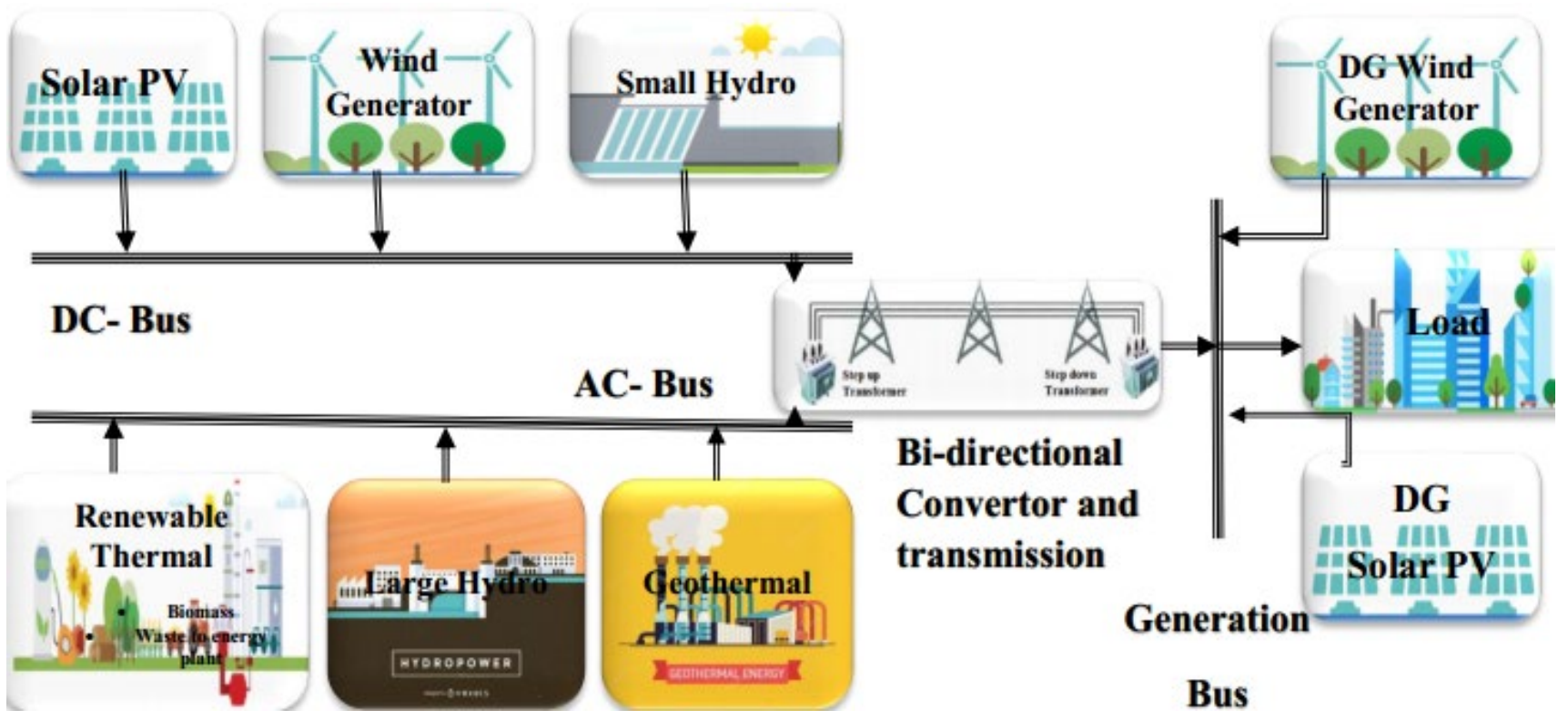

Figure 2. Schematic diagram of the proposed power system

\section{Ethiopian Power System}

Integrating renewables without considering their economic and technical challenges lead to recursive blackouts that subsequently affect the economic growth of the country [4]. Ethiopia is endowed with various renewable energy resources. The estimated potential for hydropower is 45 $\mathrm{GW}$, geothermal is $5 \mathrm{GW}$, and solar irradiation ranges from $4.5 \mathrm{kWh} / \mathrm{m} 2 /$ day to $7.5 \mathrm{kWh} / \mathrm{m} 2 /$ day [11] [12].
As of hydropower generation, large and small hydro potential estimates to $45 \mathrm{GW}$, of which $5 \%$ is only exploited. Wind potential is estimated to be $1,350 \mathrm{GW}$ but less than $1 \%$ is exploited [11]. The entire generation plan of the Ethiopian power system is depicted in Figure 3.

In a comprehensive construct, several papers presented renewable energy resource potential assessments and prospects of integrating renewable generation [8]. Hossain Mondal et al. [3] clearly articulated the prospects of improving energy efficiencies and mitigating greenhouse gasses emission from Ethiopian energy generation. 


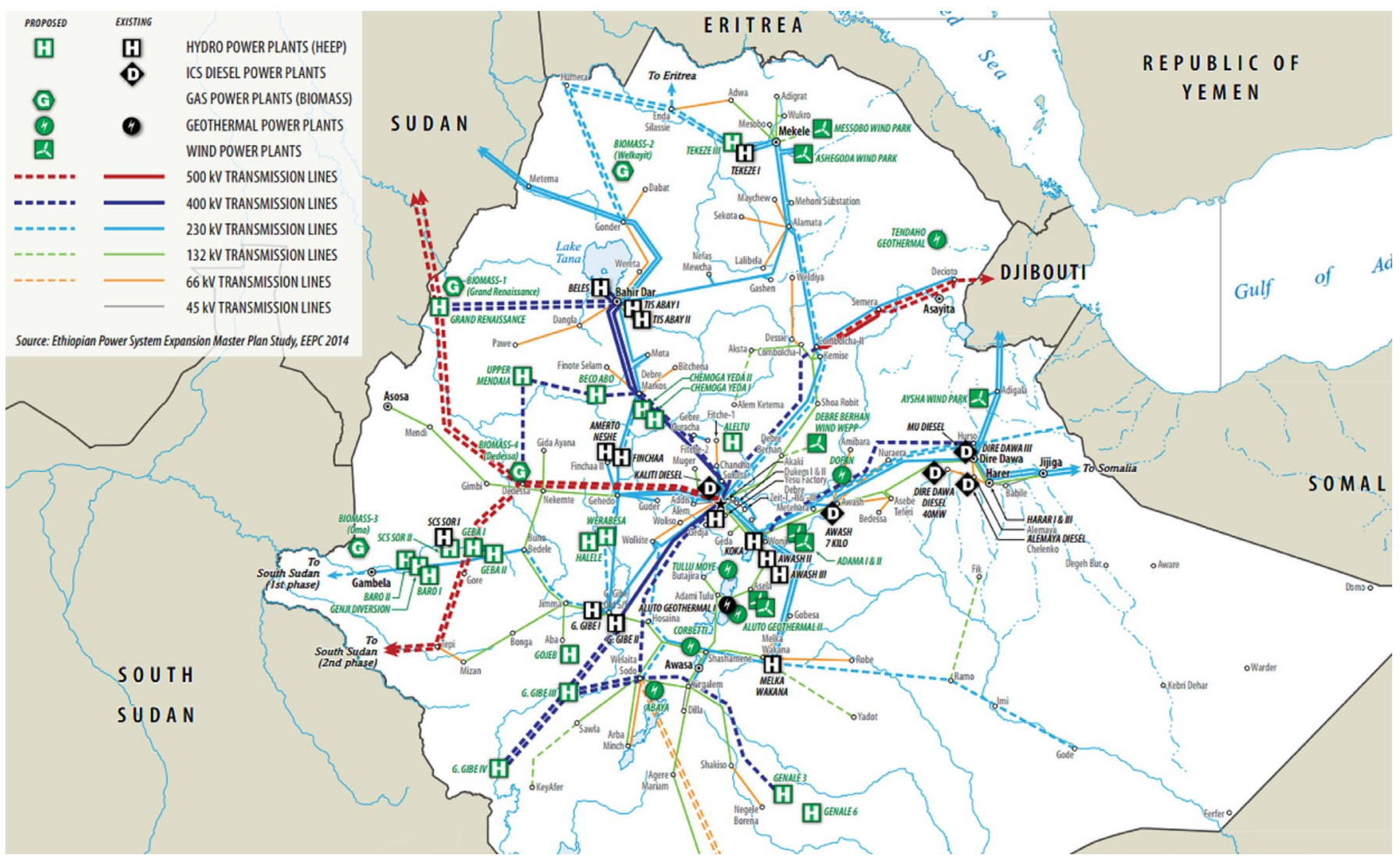

Figure 3. Location of existing and planned renewable generation stations

\subsection{Generation capacity}

The electricity grid in Ethiopia is now entirely primemoved by renewables, and the priority projects imply that this trend will continue. Geographic access to electricity is $56 \%$ with household connectivity of $25 \%$ and per capita electricity consumption of $100 \mathrm{kwh} /$ day [1] [12].

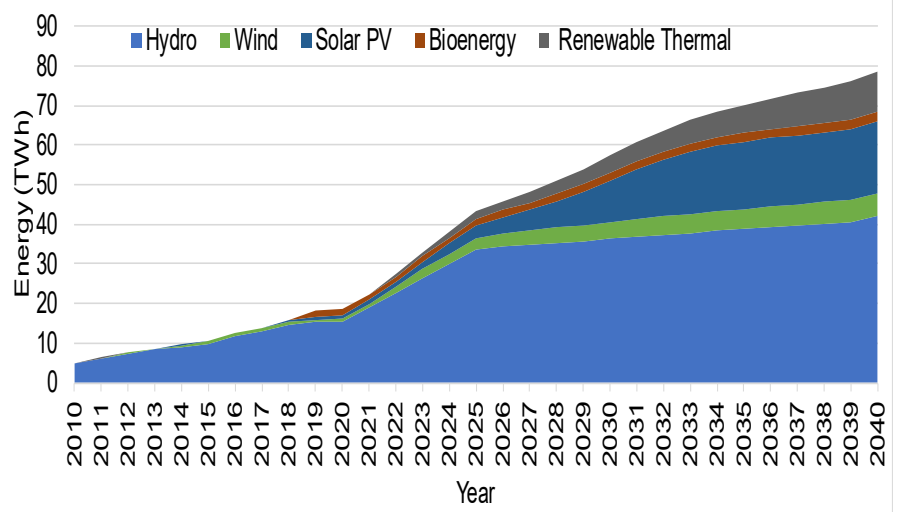

Figure 4. Annual forecasted generation capacity

From a comprehensive understanding of the Ethiopian power grid, 99 power plants as renewable energy systems are identified. These include 48 operational power, 16 plants under construction, and 35 planned. Technologywise, the planned power grid constitutes 35 hydropower plants, 18 geothermal power plants, 11 wind power plants, 9 solar power plants, and 21 renewable thermal power plants.
In this study, the operational plants and plants that are under construction were used. Hence, the considered power system constitutes 85 generating units and is dispatched for the projected year of 2025 according to the forecasted generation presented in Figure 4.

\subsection{Demand forecast}

The average annual growth in electricity demand from 2012 to 2013 was approximately $14 \%$ while electricity consumption per capita $60 \mathrm{~kW}$ in the year 2012. According to [12], an estimated $23 \%$ population had access to electricity in 2012. Ethiopia faces a significant challenge while working to achieve sustainable development. Economic growth, population growth and industrialization greatly increase electricity demand [2].

In response to these challenges, Ethiopian Electric power (EEP) is executing many projects in consideration of the demand for electricity to enhance its capacity in line with the growth of the country. The electricity demand has doubled for the past 10 years and is expected to increase by $28 \%-32 \%$ per year in the next five years. The existing plan is to reach the capacity of power generation $17.3 \mathrm{GW}$ and $21,728 \mathrm{~km}$ of transmission lines by 2020 [3] [13]. These figures do not signify the effect of variable demand, recursive blackouts and intermittent generation.

Both intermittent renewable generation and variable demand depend on weather and the type of customers. Most electric grids and utilities serve different customers in different sectors, such as residential, commercial, and industrial, as shown in Figure 5. 
The electric usage is not the same for customers that belong to different sectors, but somewhat similar for customers within the same sector [13].

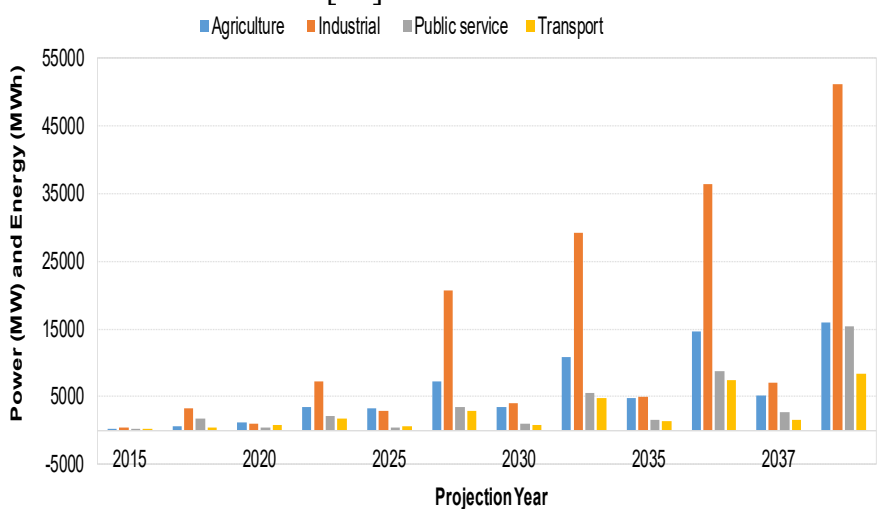

Figure 5. Sector-wise demand forecast

To cope up with the growing demand's pace, intensive study on the demand profiles, accurate short-term planning, load forecast, and demand-supply balance should be provided.

\subsection{Power Mismatch}

To dispatch a power system, it is imperative to study supply and demand profiles. Supply refers to the existing generation capacity of the power system, while demand refers to the load of the grid. Ethiopia has a final energy consumption of around 40,000 GWh, whereof domestic appliances, $4 \%$ by the transport sector and $3 \%$ by the industry consume $92 \%$ [15]. In light of this, matching the diverse characteristics of renewables to the widely varying rural needs is facilitated by employing integrated renewable generation.

Ethiopia's current grid is inadequately maintained, and grid quality and stability are already matters of concern, making the integration of renewables a heightened challenge. Employing computationally efficient OGD can overcome these challenges. For example, with large reservoirs, hydropower can store energy over weeks, months, seasons or even years.

Hydropower can therefore provide a full range of spinning reserves, non-spinning reserves, operating reserves, responsive reserves, regulation up, and regulation down required for high penetration of wind and solar [14]. To do this, optimal dispatch and reserve allocation are needed. The operator needs to know when to dispatch the hydro unit instead of solar or wind. This way, the so-called 'duck curve' challenge of solar PV generation can be solved.

\section{Mathematical Framework}

\subsection{Problem formulation}

Relations between the power generation cost and the operating cost rely on power flow output and forecasted values [9] [14] [15]. Problem formulation thus starts from the optimization perspective of the OGD mathematical model. The general optimization problem form for OGD is:

$$
\text { optimizef }(x), x \in R
$$

Subject to

$$
\begin{aligned}
& h_{k}(x)=0 \forall 1,2 \ldots m \\
& g_{l}(x) \leq 0 \forall 1,2 \ldots L
\end{aligned}
$$

Where $h_{k}(x)$ represents a set of equality constraints $g_{l}(x)$, represents a set of inequality constraints, and $f(x)$ is the objective function that optimizes $\mathrm{x}$. In a practical power system, the OGD problem is non-linear and multi-objective due to operational constraints [20] [19]. Objective function should minimize the non-detailed formulation of the OGD problem due to unnecessary assumptions that can lead to a limitation in the modelling of large-scale power systems [21]. In this regard, multi-objective optimization is favoured. The general form of multi-objective optimization is then:

$$
\text { Optimizef }(x)=\left(f_{1}(x), f_{2}(x), f_{\text {Nobj }}(x)\right.
$$

Subject to

$$
\begin{gathered}
g_{l}(x)=0 \forall i=1,2 \ldots m \\
h_{k}(x) \leq 0 \forall k=1,2, \ldots K
\end{gathered}
$$

$x_{i}(1) \leq x_{i} \leq x_{i}(0)$

Where $f_{1}(x), f_{2}(x), f_{\text {Noty }}(x)$ are different objective functions denoting the involved renewables and $x_{i}$ denotes the security level constraints of the power system.

OGD for Hydro: To formulate an economic dispatch problem, the first objective function $\mathrm{f}_{1}(\mathrm{x})$ in equation (4) represents the objective function of hydropower generation plants [14] [22].

$$
\min f_{1}(x)=C_{h} \sum_{i=1}^{N_{h g}} P_{h g j}(t)
$$

Where $C_{h}$ denotes hydropower generation cost, $P_{h g j}$ represents hydropower output at the $\mathrm{i}^{\text {th }}$ unit, and $N_{h g}$ is the number of committed hydropower plants. 
OGD for Wind: The behaviour of wind speed at a given area or location can be quantified as a probability distribution function [23] [24]. Dispatch wise, its corresponding objective function is $\mathrm{f}_{2}(\mathrm{x})$.

$$
f_{2}(x)=C_{w} \sum_{i=1}^{N_{n i z}} P_{p j i}(t)+\sum_{i=1}^{24} \sum_{i=1}^{N_{v e n}} C_{R}+C_{P}
$$

Where $C_{w}, P_{w g j}$ and $N_{W G}$ represent wind power generation cost, wind power output at the $\mathrm{i}^{\text {th }}$ unit, and the number of committed wind generating units. $C_{R}$ and $C_{P}$ represent the reserve cost and penalty cost coefficients of wind power generation, respectively.

OGD for Solar $P V$ : the solar power output depends on the solar irradiance of a particular site [25] and its objective function considered as the third objective function of (4) is represented by $\mathrm{f}_{3}(\mathrm{x})$ :

$f_{3}(x)=C_{s} \sum_{i=1}^{N_{s g}} P_{s g} j(t)+\sum_{t=1}^{24} \sum_{i=1}^{N_{s g}} C_{R}+C_{P}$

Where for $0<G<R$ ca:

$P_{s g} j(t)=\sum_{t=1}^{24} \sum_{i=1}^{N_{s g}}\left(C_{R}+C_{P}\right)$

$C_{R}$ and $C_{P}$ represent the reserve cost function and penalty cost function of solar PV generation, respectively. The reserve cost function determines the debit produced from variable solar radiation [23].

OGD for Renewable Thermal: Renewable thermal plants in this context refer to plants that are prime moved by renewable sources. Despite the difference in their constraints, renewable thermal plants have similar objective functions [11] [26]. The economic dispatch objective function of thermal power generation cost $\left(F_{t h}\right)$ is a quadratic function of a coefficient measure of losses $\left(a_{i}\right)$, coefficient representing fuel cost $\left(b_{i}\right)$, and coefficient representing operating and maintenance costs that include salary and wages $\left(c_{i}\right)$. Denoting solar thermal power generation cost, geothermal generation cost, and biomass generation cost by $F_{S t h}, F_{G t h}$ and $F_{B t h}$ respectively; the total objective function for renewable thermal power generators with their corresponding power outputs, $P_{S t h}, P_{G t h}$, and $P_{B t h}$ is given by:

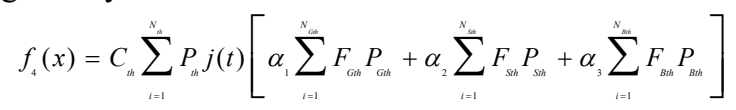

Where

$$
\begin{aligned}
& F_{t h}=a_{i} P_{t h}^{2}+b_{i} P_{t h}+c_{i} \\
& F_{G t h}=a_{i} P_{G t h}{ }^{2}+b_{i} P_{G t h}+c_{i} \\
& F_{S t h}=a_{i} P_{S t h}{ }^{2}+b_{i} P_{S t h}+c_{i} \\
& F_{B t h}=a_{i} P_{B t h}{ }^{2}+b_{i} P_{B t h}+c_{i}
\end{aligned}
$$

Where $P_{t h}, P_{G t h}, P_{S t h} \& P_{S t h}$ denote thermal power output, geothermal power output, solar power output, and biomass power output. Weight factors of unit costs between $0 \& 1$ are represented by $\alpha$.

Security index; Security index as an objective function that shows the severity of contingency during outages is considered. The security index is introduced as an extension and improvement of OGD problem formulation in [27].

$$
f_{s}(x)=f_{S L}=\sum_{i=1}^{N L}\left(\frac{P_{\text {Gactive }}}{P_{\text {Gactive }}^{\max }}\right)^{2 m}
$$

Where $\mathrm{N}_{\mathrm{L}}$ denotes the total number of transmission lines $P_{\text {Gactive }} \& P_{\text {Gactive }}^{\max }$ represent active power flow and maximum active power flow at the $\mathrm{k}^{\text {th }}$ line, respectively.

\subsection{Constraint formulation}

In power systems, continuously respected operation constraints and limits ensure the reliable and secure operation of the system.

1. Demand and generation balance

$$
P_{D}+P_{L}=\sum_{i=1}^{N_{h g g}} P_{h g}+\sum_{i=1}^{N_{w g}} P_{w g}+\sum_{i=1}^{N_{s g}} P_{s g}+\sum_{i=1}^{N_{t h}} P_{t h}
$$

Demand and generation balance clarifies that the total generation of hydro generating units (Phg), wind generating units(Pwg), solar units(Psg), and thermal units(Pth) should be equal to the sum of total demand $\left(\mathrm{P}_{\mathrm{D}}\right)$ and power $\operatorname{loss}\left(\mathrm{P}_{\mathrm{L}}\right)$.

2. Generation limits

$$
\begin{aligned}
& P_{i}^{\min } \leq P_{i} \leq P_{i}^{\max } \\
& P_{\min } \leq 0.00981 \eta_{i} H_{i j} Q_{i j} \leq P_{\max } \\
& 0 \leq P_{w} j(t) \leq P_{w r} \\
& 0 \leq P_{s} j(t) \leq P_{s r} \\
& 0 \leq P_{h} j(t) \leq P_{h r}
\end{aligned}
$$

$\mathrm{P}_{\mathrm{wr}}, \mathrm{P}_{\mathrm{sr}}, \mathrm{P}_{\mathrm{hr}}$, and $\mathrm{P}_{\mathrm{i}}$ denote the rated wind power output, rated solar power output, rated hydropower output, and power output of the $\mathrm{i}^{\text {th }}$ generating unit, respectively.

3. Prohibited operating Zones

$$
\begin{aligned}
& P_{i}^{\min } \leq P_{i} \leq P_{i}^{L j} \forall j=1,2 \ldots N_{P o z} \\
& P_{i}^{V_{j}-1} \leq P_{i} \leq P_{i}^{l j} \\
& P_{i}^{V_{j}-1} \leq P_{i} \leq P_{i}^{\max }
\end{aligned}
$$

Modern generators have prohibited operating zones $\left(\mathrm{N}_{\mathrm{poz}}\right)$ for determining feasible operating zones. 
4. Transmission constraints:

$P_{L}=\sum_{i=1}^{n} \sum_{j=1}^{m} P_{g i} B_{i j} P_{g j}=B_{o o}+\sum_{i=1}^{n} B_{i o} P_{g i}+\sum_{i=1}^{n} \sum_{j=1}^{m} P_{g i} B_{i j} P_{g j}$

Where

$$
\begin{gathered}
B_{i j}=\frac{\cos \left(\theta_{i}-\theta_{j}\right) R_{i j}}{\cos \phi_{i} \cos \phi_{j} V_{i} V_{J}} \\
B_{o o}=\sum_{i=1}^{n} \sum_{j=1}^{m} P_{D i} B_{i j} P_{D j} \\
B_{i j}=-\sum_{j=1}^{m}\left(B_{i j}+B_{j i}\right)
\end{gathered}
$$

The power transmission losses depend on the flows in the branches and thus on the net injections and Kron's loss equation better describes power injection parameters.

\section{Security limits}

Security limits refer to the fact that apparent power flow through the transmission line $\left(s_{l}\right)$ must be restricted by its upper limit $\left(s_{l}^{\max }\right)$ for all security levels $\left(N_{L}\right)$. The security level thus depends on the credibility of contingencies $\left(\phi_{l} P(t)\right)$.

$$
\begin{aligned}
& S_{1} \leq S_{1}^{\max } \forall l=1,2 \ldots N_{L} \\
& \phi_{j} P(t)>o \forall j=1,2 \ldots N_{C}
\end{aligned}
$$

6. Generator ramp rate limits

$$
\max \left(P_{i}^{\min }, P_{i}^{t-1}-D R_{i}\right) \leq P_{i}(t) \leq \min \left(P_{i}^{\operatorname{mix}}, P_{i}^{t-1}+D R_{i}\right)
$$

Increasing and decreasing the output of renewable generation is limited to the amount of dependable power due to the physical and mechanical restrictions of each generating unit.

7. Spinning reserve limits

To have a primary frequency response to variable demand, a minimum spinning reserve value must be set aside.

$$
\sum_{i=1}^{N_{G}} S_{R i} \geq S_{S r}
$$

Where $S_{R i}$ is the fraction of the total spinning reserve of the power system $\left(S_{S r}\right)$ allocated to the generating unit i.

8. Water discharge and reservoir limits:

For hydrothermal generating units, bounds by the restrictions of their storage reservoirs must be considered.

$$
\begin{gathered}
X_{i}^{\min } \leq X_{i} \leq X_{i}^{\max } \\
V_{i}^{\min } \leq V_{i} \leq V_{i}^{\max } \\
Q_{i}^{\min } \leq Q_{i j} \leq Q_{j}^{\max }
\end{gathered}
$$

$$
\begin{aligned}
& V_{i}^{\min } \leq V_{i j} \leq V_{j}^{\max } \\
& V_{t, j+1}=V_{v}-\left(Q_{v}-q_{j}+S_{v i}\right) \Delta t+\sum\left(Q_{i j}+S_{\psi}+I_{j}\right) \Delta t
\end{aligned}
$$

9. Penetration rate constraints

$$
P_{w} j(t)+P_{s} j(t)+P_{h} j(t)+P_{t h} j(t) \leq \Psi P_{D}
$$

In this study, a penetration rate of $98 \%$ for the Ethiopian power system is considered.

\section{Hybrid Genetic Algorithm-Hopfield Neural Network solution method}

\subsection{Genetic Algorithms}

Genetic algorithm (GA) is a global search technique based on the mechanics of natural selection that searches from population to population with features of strong adaptability and implicit parallelism [37] [38]. First, initialize the number of generating units $\mathrm{N}$ and population size, NP and specify credible contingencies and. Population size and dimension randomly generate an initial vector Ptij. Ptij is the real power value of jth unit of the ith population randomly generated within the operating limits using [39]. $P_{i j}^{t}=P_{i}^{\min }+\operatorname{rand}(0,1)\left(P_{i}^{\max }-P_{i}^{\min }\right)$

Evaluate the fitness value of each vector $\mathrm{P}_{\mathrm{ij}}^{\mathrm{t}}$ according to the fitness function given below

$$
F_{A}=-\left(f_{1}(x)+f_{2}(x)+f_{3}(x)+f_{4}(x)+f_{\text {Penality }}+f_{\text {Re serve }}+f_{\text {loss }}\right)
$$

Perform mutation operation on the target vectors to obtain new parameter vectors called mutant vectors using

$Z_{i j}=P_{i j}^{t}+F\left(P_{R i j}^{t}-P_{R j i}^{t}\right)$

Perform crossover operation to create trial vectors from mutant and target vectors. If the generated random number value is less than or equal to the assumed value of the crossover constant, then the mutant vector is chosen, else the parent vector is chosen as given below. The assumed crossover constant $\left(C_{R}\right)$ should be within the range of $(0,1)$ [28].

$U_{i j}^{t+1}=\left\{\begin{array}{l}Z_{i j}, \text { if }\left(R_{i j}\right) \leq C_{R} \\ P_{i j}, \text { if }\left(R_{i j}\right) \geq C_{R}\end{array}\right\}$

Decide members to constitute the population of the next generation $(t+1)$. The new vector $U_{i j}(t+1)$ is selected based on the comparison of fitness of both target vector, $\mathrm{P}_{\mathrm{i}}$ and trial vector, $\mathrm{U}_{\mathrm{i}}$. Compute generation after generation to meet the stopping criteria $t_{\max }[29]$.

\subsection{Hopfield neural network Approach}

The Hopfield Neural Network (HNN) is a recurrent artificial neural network popularized by John Hopfield in 1982, in which networks serve as associative memory systems with binary threshold nodes. The output of each neuron is then supplied to all other neurons. 
The process continues until a stable state that represents the network output is reached. HNN is a widely used model for solving combinatorial optimization problems [19]. In Hopfield Networks, an attractor pattern is a final stable state, a pattern that cannot change any value within it under updating [30].

$$
V_{i}^{0}=P_{G i}^{\min }+\operatorname{rand}\left(P_{G i}^{\max }-P_{G i}^{\min }\right)
$$

The initial values of inputs for these neurons are calculated by the inverse sigmoid functions based on the initial outputs of the continuous neurons representing power outputs of generating units [31].

$$
u_{i}^{0}=\frac{1}{2 \sigma} \ln \left(\frac{V_{i}^{0}-P_{G i}^{\min }}{P_{G i}^{\max }-V_{i}^{0}}\right)
$$

The inputs to the neuron come from two sources, one from the external inputs Ii and the other from the other neurons $\mathrm{Vj}$. Where: $\mathrm{U} \mathrm{i}$ is the total input to neuron $\mathrm{i}$, Tij is the interconnection conductance from the output of neuron $j$ to the input of neuron i, Ii denotes external input to neuron i, and $\mathrm{Vj}$ stands for the output of neuron $\mathrm{j}$. The continuous model of the HNN is based on continuous variables [32]. The most important point in solving any optimization problem using $\mathrm{HNN}$ is the mapping of the problem objectives and constraints on the energy function of the network [30]. The objective function for the generation dispatch problem has two parts: i) the operation and generation cost minimization part ii) the generation and computation error minimization part. To solve the generation dispatch problem the energy function is defined by combining the objective function with constraints as [32] [16]:

$$
E=A\left(P_{D}+P_{L}-\sum_{i=1}^{N} P_{G}\right)^{2}+B \sum_{i=1}^{N_{G}}\left(a_{i}+b_{i} P_{G i t i}+c_{i} P_{\text {cioit }}{ }^{2}\right)+\left(\frac{C}{2}\right) P_{L}{ }^{2}
$$

The synaptic strength and external input are obtained by mapping the energy function. By changing the output of unit $\mathrm{i}$ from $\mathrm{P}_{\mathrm{Gio}}$ to $\mathrm{P}_{\mathrm{Gi}}$, and the transmission loss change from $\mathrm{P}_{\mathrm{Lo}}$ to $\mathrm{P}_{\mathrm{L}}$ the loss can be represented by[31]:

$$
P_{L}=P_{L o}+d P_{L} \cong P_{L o}+\sum_{i=1}^{N} I_{L i o}\left(P_{G i}-P_{\text {Gio }}\right)
$$

The energy function of HNN is defined by combining the objective function and the corresponding constraint function, employing weight coefficients, which determine the weightage of each factor. This starts with the energy function of HNN given by:

$$
E=-\frac{1}{2} \sum_{i=1}^{N} \sum_{j=1}^{N} T_{l j} V_{i} V_{j}-\sum_{i=1}^{N} I_{i} V_{i}
$$

The time derivative of this energy function should be negative, so the network always moves in such a direction that the function converges to a minimum. To solve OGD using $\mathrm{HNN}$, the penalty function method is used.

$$
E=\frac{A}{2}\left(\sum_{i=1}^{N}\left(a_{i} P_{G \text { Ghi }}{ }^{2}+b_{i} P_{G \text { Ghi }}+c\right)\right)+\frac{B}{2}\left(P_{L}+P_{D}-\sum_{i=1}^{N} P_{G i h i}\right)^{2}
$$

This energy function consists of objective function also known as cost functions and design constraints function.

$$
\begin{aligned}
& P_{L}=P_{L o}+d P_{L} \cong P_{L o}+\sum_{i=1}^{N} I_{L i o}\left(P_{G i}-P_{G i o}\right) \\
& \frac{\partial P_{L}}{\partial P_{G i} P_{C o}}=2 \sum_{i=1}^{N} B_{i j} P_{G j o}\left(P_{G i}-P_{G i o}\right) \\
& P_{L}=\sum_{i=1}^{N} \sum_{j=1}^{N} P_{G i o} B_{i j} P_{G j o}+2 \sum_{i=1}^{N} \sum_{j=1}^{N} B_{i j} P_{G j o}\left(P_{G i}-P_{G i o}\right)
\end{aligned}
$$

To map this equation into $\mathrm{HNN}$, the computation should start with equating (57) and (58), so that the following set of equations is obtained.

$$
\begin{gathered}
T_{i i}=-A a_{i}-B, T_{i j}=-B \\
I_{i}=B\left(P_{D}-P_{L}\right)-\frac{\lambda}{2} b_{i} \\
I_{i}=A\left(P_{D}+P_{L}\right)-\frac{B b_{i}}{2}
\end{gathered}
$$

A and B being weighting factors, A varies from 0.1 to $3, \mathrm{~B}$ is set to 1 , and is set to 0.000055 . A \&B should be greater than or equal to zero. The relation that updates these values is called an adaptive calculation of weighting factors.

$$
\begin{aligned}
& A=\frac{I_{M}+0.5 B b_{m}}{P_{G}} \\
& B=\frac{I_{m}-A P_{D}}{0.5 b_{m}}
\end{aligned}
$$

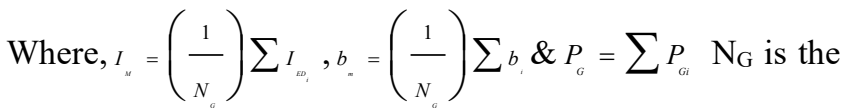
number of committed generating units. In the selection procedure of weighting factors, $\mathrm{A}$ is associated with power mismatch $\left(\mathrm{P}_{\mathrm{m}}\right)$, as it is assigned the highest priority over the other terms [22].

$$
\begin{aligned}
& A\left(P_{m}\right)^{2} \geq B\left(\Delta f_{T}\right) \\
& A \geq B\left(\Delta f_{T}\right) /\left(P_{m}\right)^{2}
\end{aligned}
$$

This means $\mathrm{A}$ is determined from any value of $\mathrm{B}$. To determine the value of weighting factor $\mathrm{C}$.

$$
C=2 A P_{m}
$$

\subsection{Hybrid genetic algorithm-Hopfield neural network Approach}

Hybrid methods are a merger of two or more optimization algorithms to improve the overall performance of a single or multi-objective optimization problem. The main goal of developing hybrid methods is to achieve an improvement in terms of complexity and computational effort reduction on one hand and increasing the accuracy and robustness of the solution on the other hand. 
With the increasing interest in hybrid optimization methods, substantial articles have been published. Hybrid methods including bacterial foraging optimization that is Nelder-Mead hybrid algorithm [33], improved harmonic search, and hybrid ACO-ABC HS algorithm [34] have introduced an efficient and effective optimal solution to the SCED problem [16]. Stephen Frank et al. [35] have chronicled a bibliographic survey of papers with a perspective on non-deterministic hybrid methods for solving optimal power flow problems.

This paper proposes OGD of Ethiopian power system using a robust and computationally intelligent GA-HNN approach adopted from [16] and [32], hybridization of Hopfield neural network, and improved genetic algorithms, which takes into account the intermittency of renewables and handles probable contingencies.

The general working algorithm for GA-HNN is:

1. Write separate objective functions and constraint functions.

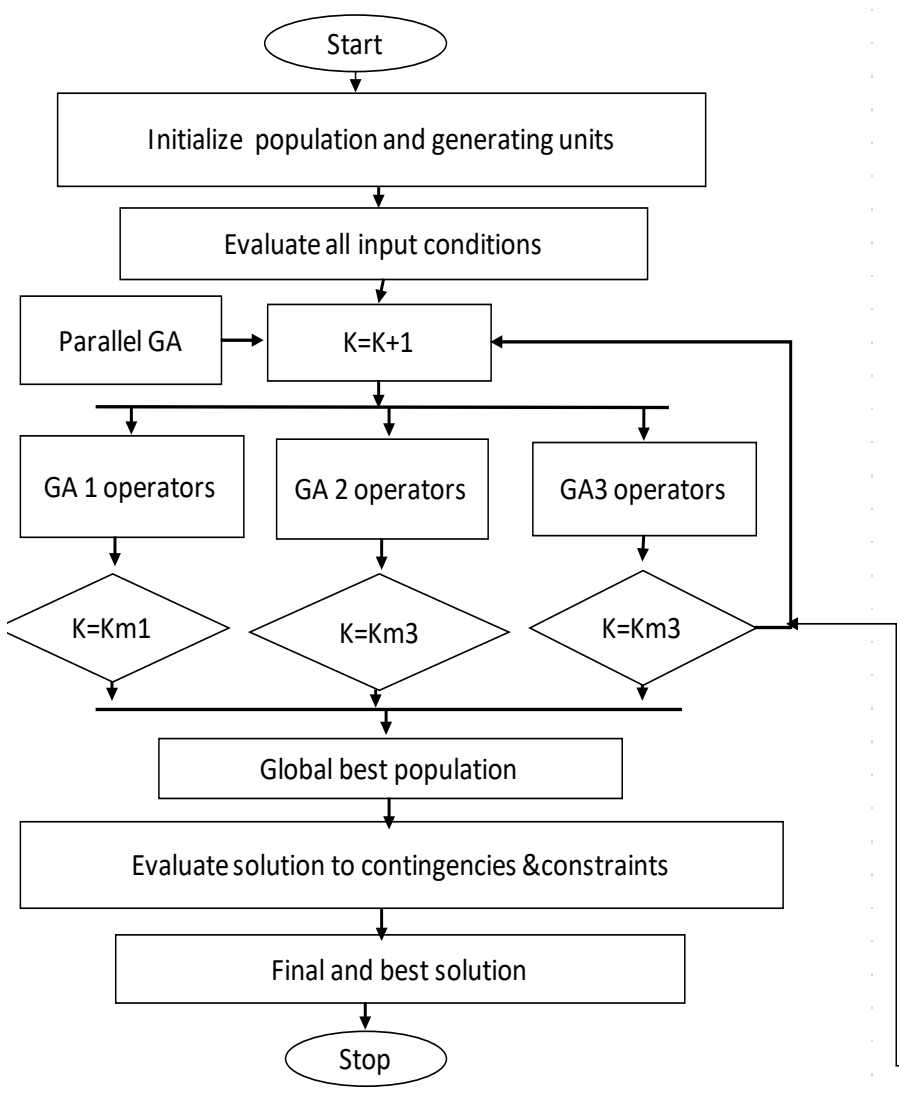

2. Enter system data and analyse inputs using Weibull PDF equations and HNN predictive control.

3. Select A, B, $\lambda$ and calculate values in equations ( 58-65)

4. Determine the attractor pattern of the final state as in equations (49 and 50)

5. Map the OGD objective functions to the HNN using penalty function weights as mathematically represented in equation (54)

6. Run adaptive calculations of weighting factors (equations 61-65)

7. Initiate genetic algorithms by selecting parameters such as population size and number of generations

8. Compute parallel and consecutive genetic algorithms \& check if the global best solution satisfies constraints and contingencies.

9. Display final and best solution

Write separate objective functions(equations $7,18,20,25$ ) and constraint functions (equations 26-40)

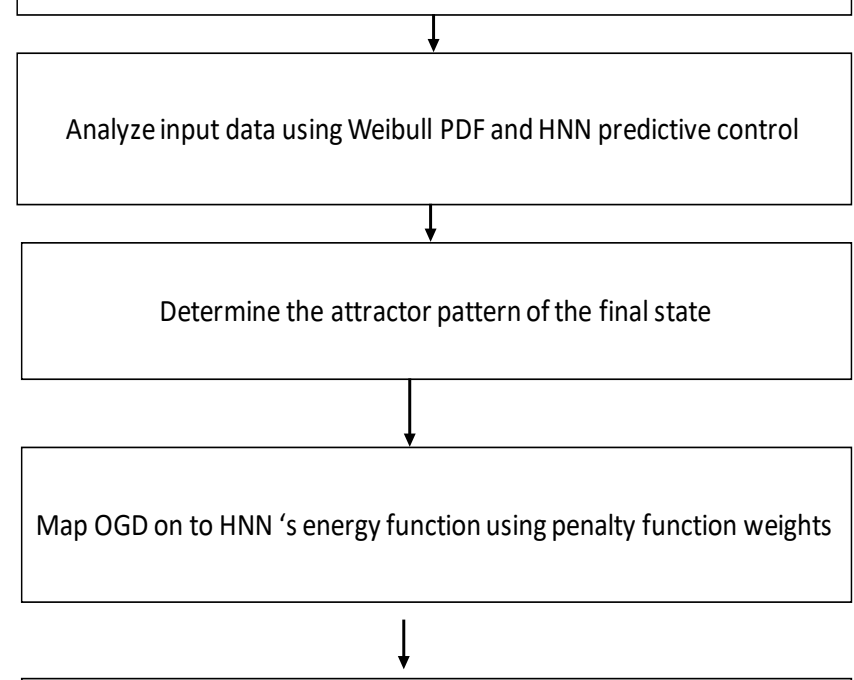

Run adaptive calculations of weighting factors and use the HNN energy function as GA fitness function

Figure 6. GA-HNN flow chart

\section{Results and discussions}

The results of optimal generation dispatch of the Ethiopian power system using GA-HNN obtained from MATLAB are presented below. Predictive control enables the Hopfield net to lower the energy state that the net should remember. This way the net can recover from a distorted input to a trained state that can withstand contingencies as shown in Figure 2. Based on the errors shown in Figure 7, credible contingencies with higher error values are selected as credible contingencies for training. 

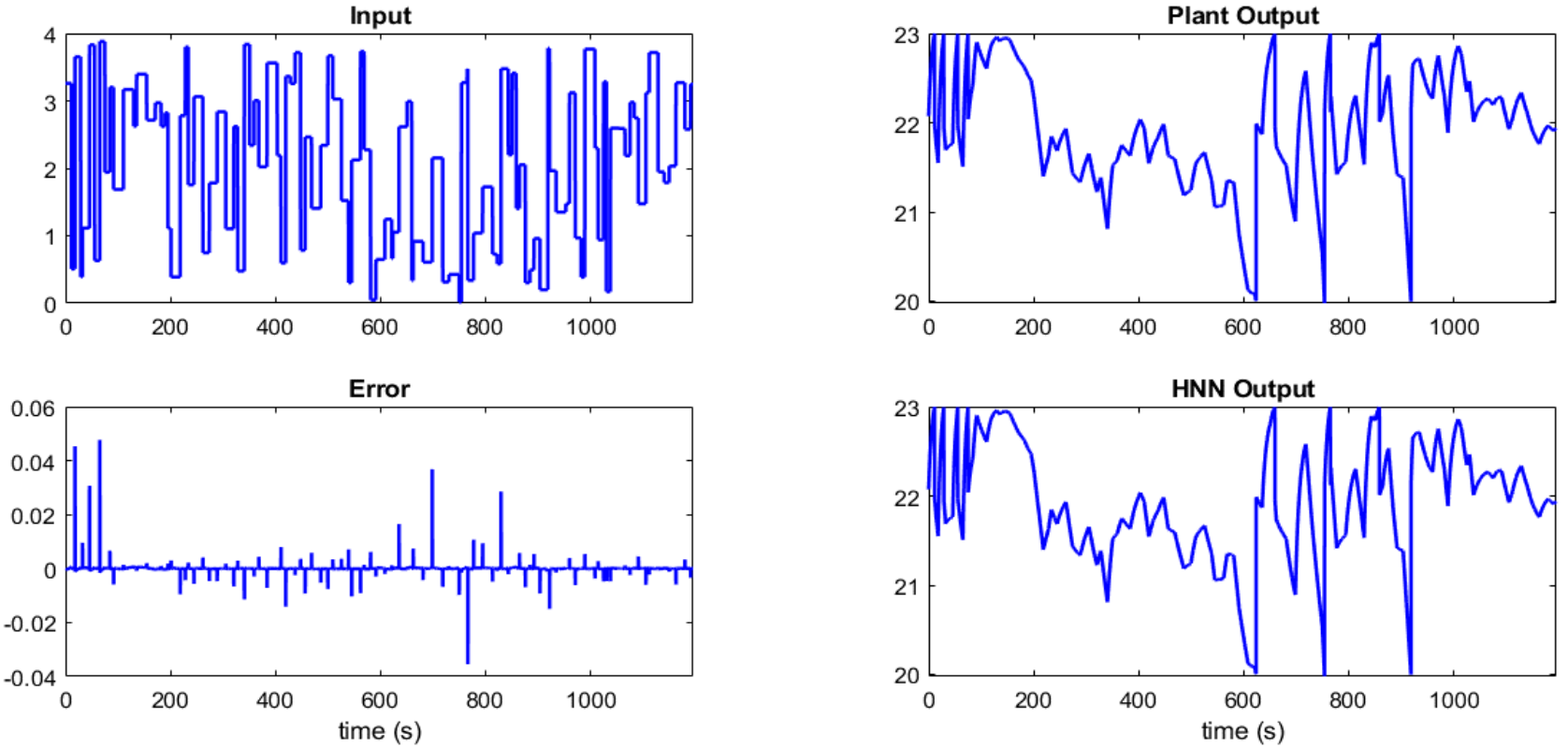

Figure 7. Predictive control of variable resources using neural networks in compliance with Weibull PDF
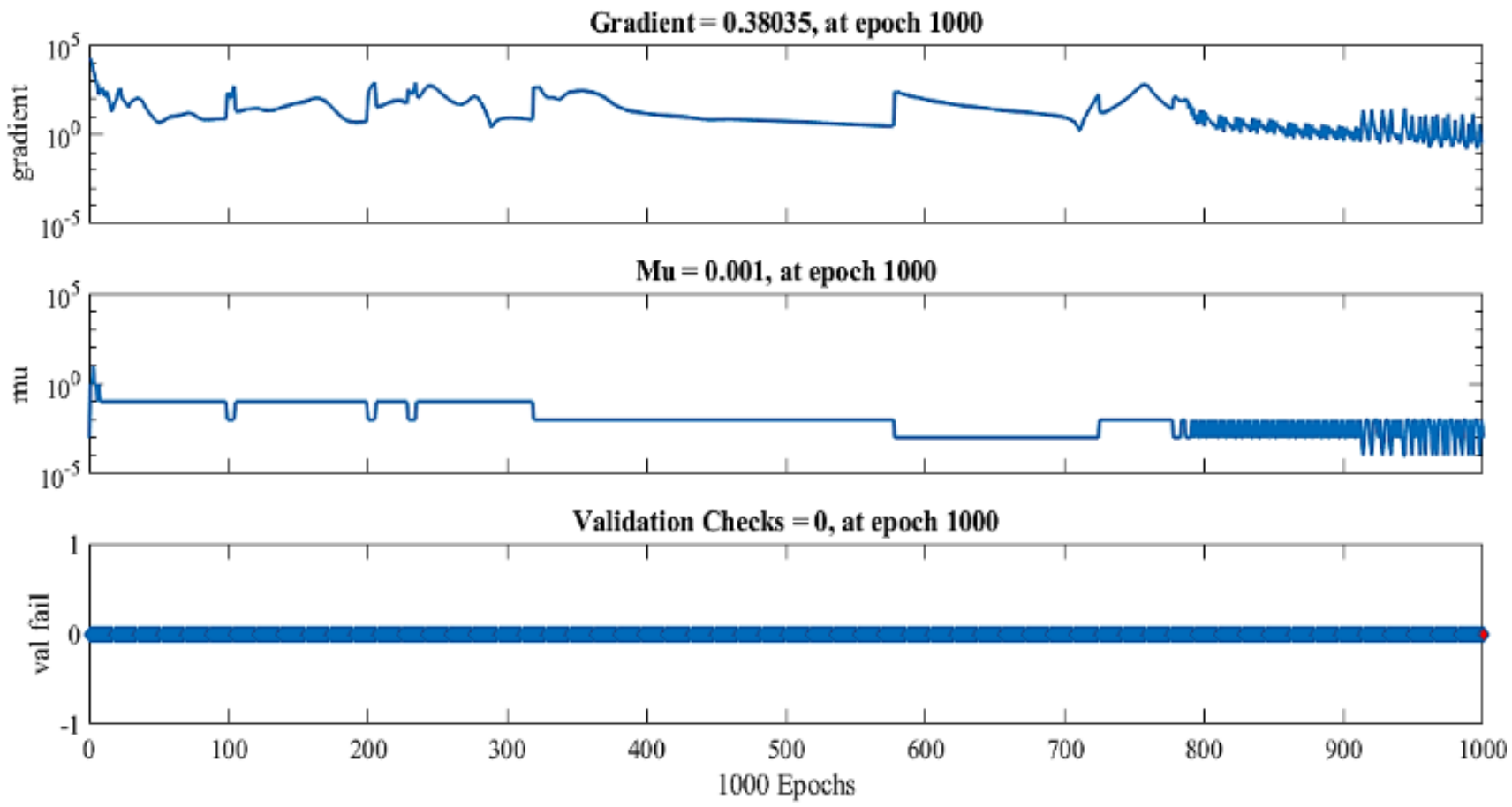

Figure 8. Data training evaluation and validation using HNN

Figures 8 and 9 present the data training evaluation and validation, the time-series response of training the create network with renewable penetration effects to the
Ethiopian power system. It can be seen that the demand and supply are affected by the intermittency and variability of renewables. 

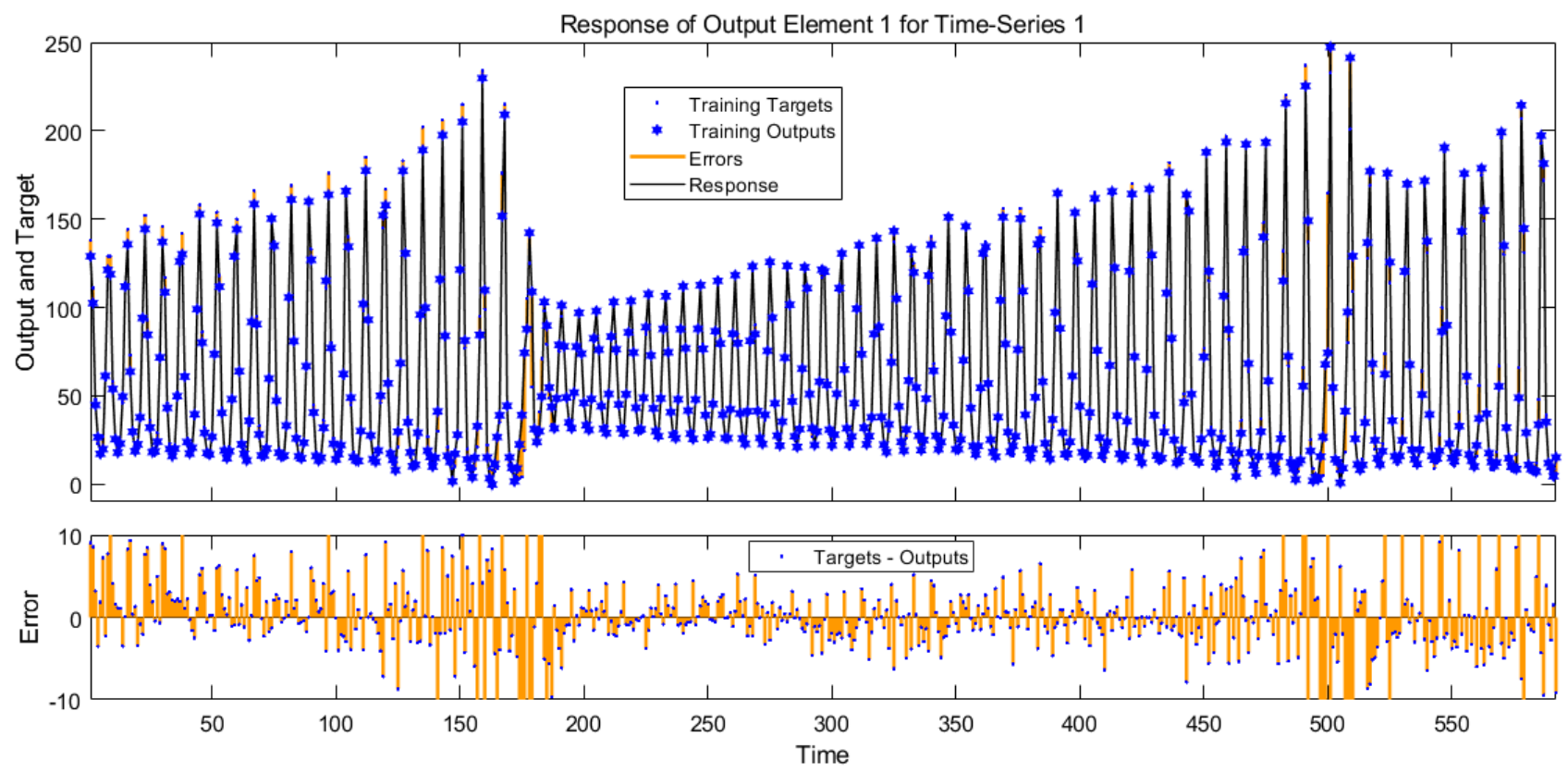

Figure 9. Time series response of training the created $\mathrm{HNN}$

To practically interpret the results, unit commitment input, forecasted data evaluated by predictive control of HNN, the number of recursive blackouts, and demand profile are integrated within the proposed OGD solution. There is an important difference in load between weekdays and weekends. Furthermore, Mondays and
Fridays being adjacent to weekends can have structurally different loads than Tuesday through Thursday. Day and night also have a different share of load and generation effects. Figure 9 thus helps to grasp the effect of weekend demand profiles on the OGD of the power grid.

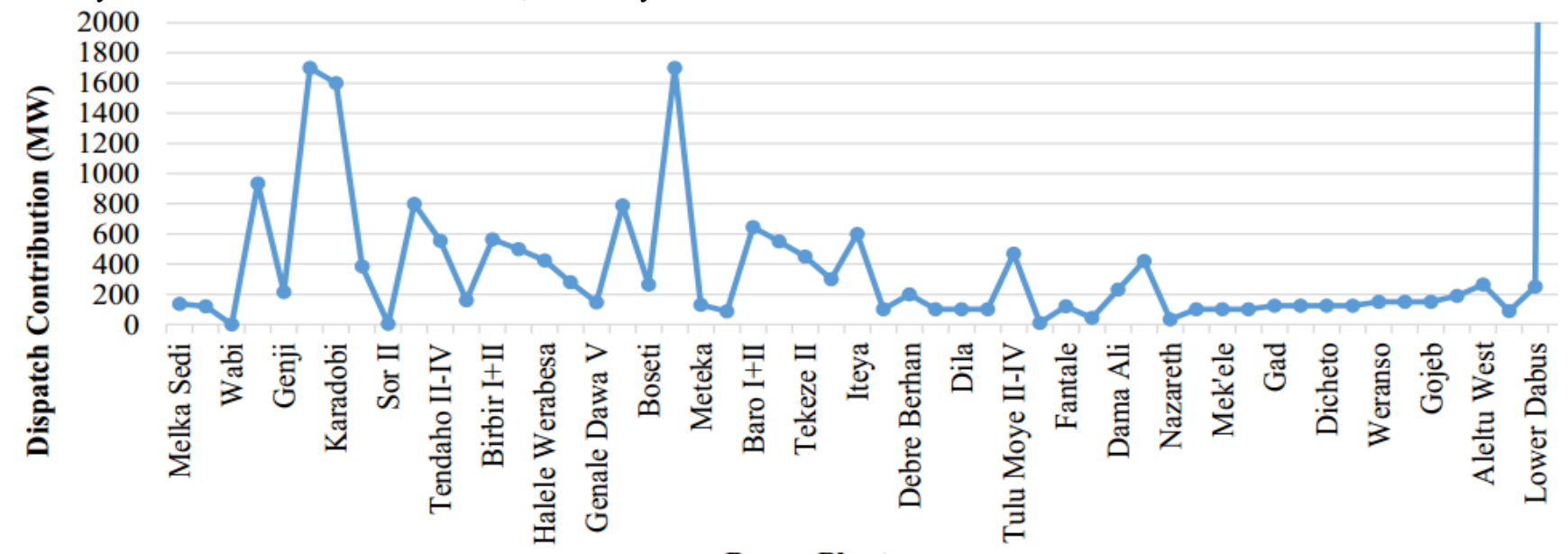

Power Plants

Figure 10. Generation dispatch share of Ethiopian power stations 


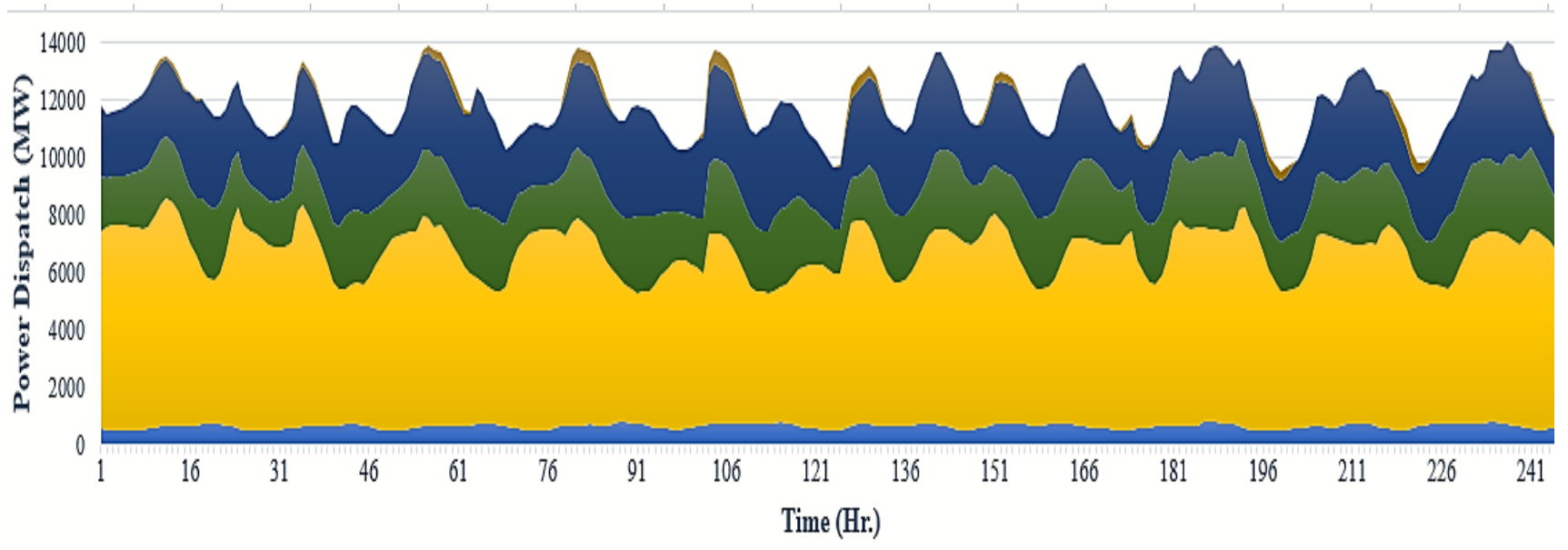

$\square$ Renewable thermal generating units $\quad$ Hydro generating units $\quad \square$ Geothermal Generating units $\quad$ Wind generating units $\quad$ Solar Pv Generating units

Figure 11. Ethiopian Renewable Energy Systems dispatch

OGD is important for scheduling when/which generator to dispatch, determining how much reserve is needed for spinning, standby, ramping, and contingency. Figure 10 presents dispatch contributions from Ethiopian existing power plants that participated in alleviating the recursive blackouts. In Ethiopia, the weather does not significantly
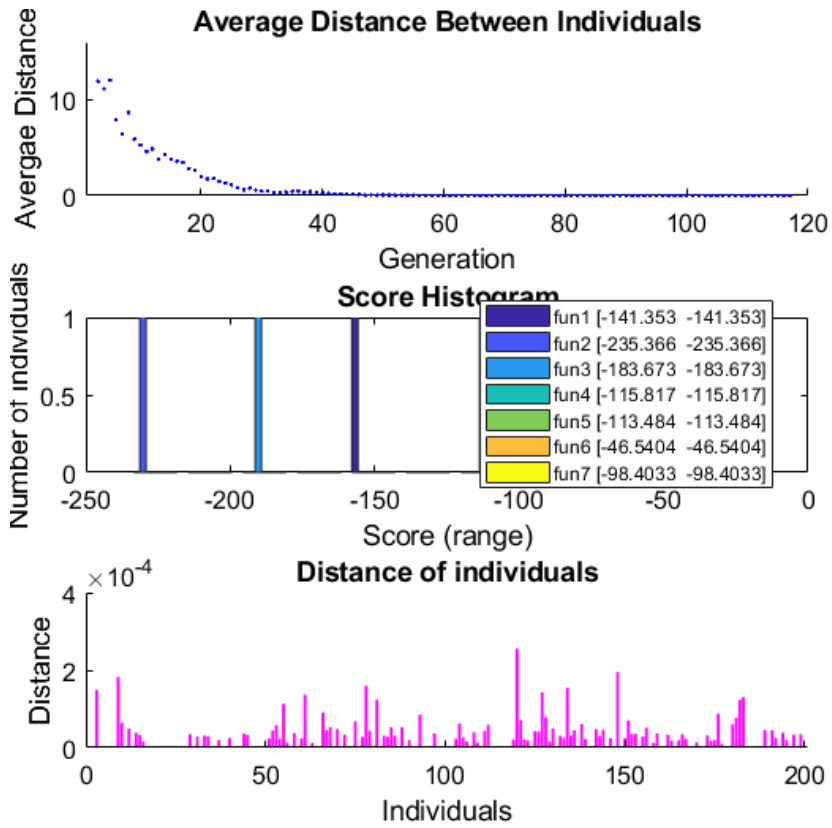

vary throughout the year. Apart from solar PV generation, therefore, demand seasonality on the grid is minimal. Here, the residential demand is characterized by lighting, cooking, and heating, and since the peak is in the evening, their contribution to the system peak is significant.
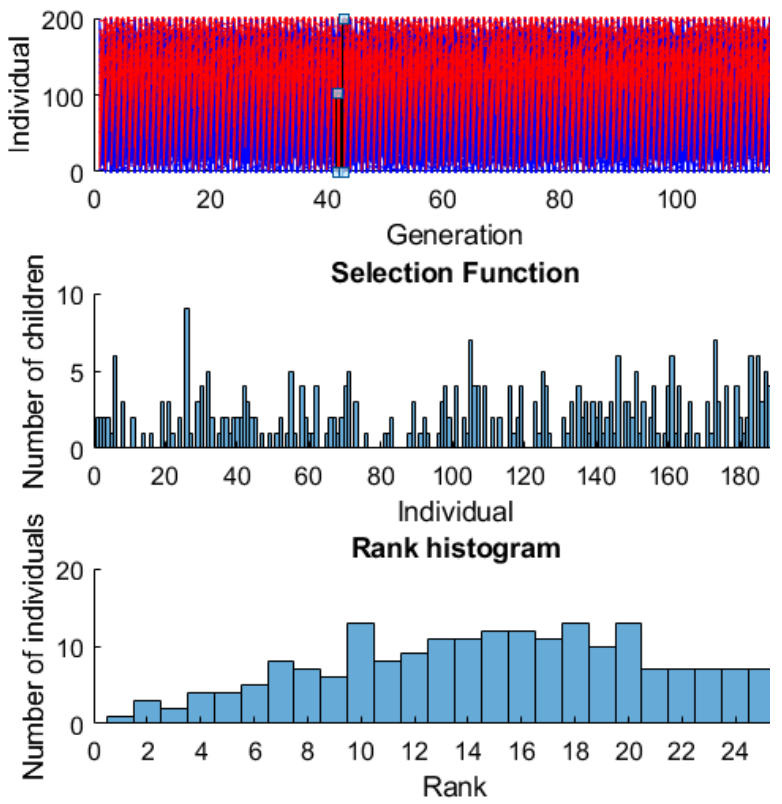

Figure 12. Results showing HNN enhanced GA features and properties. 


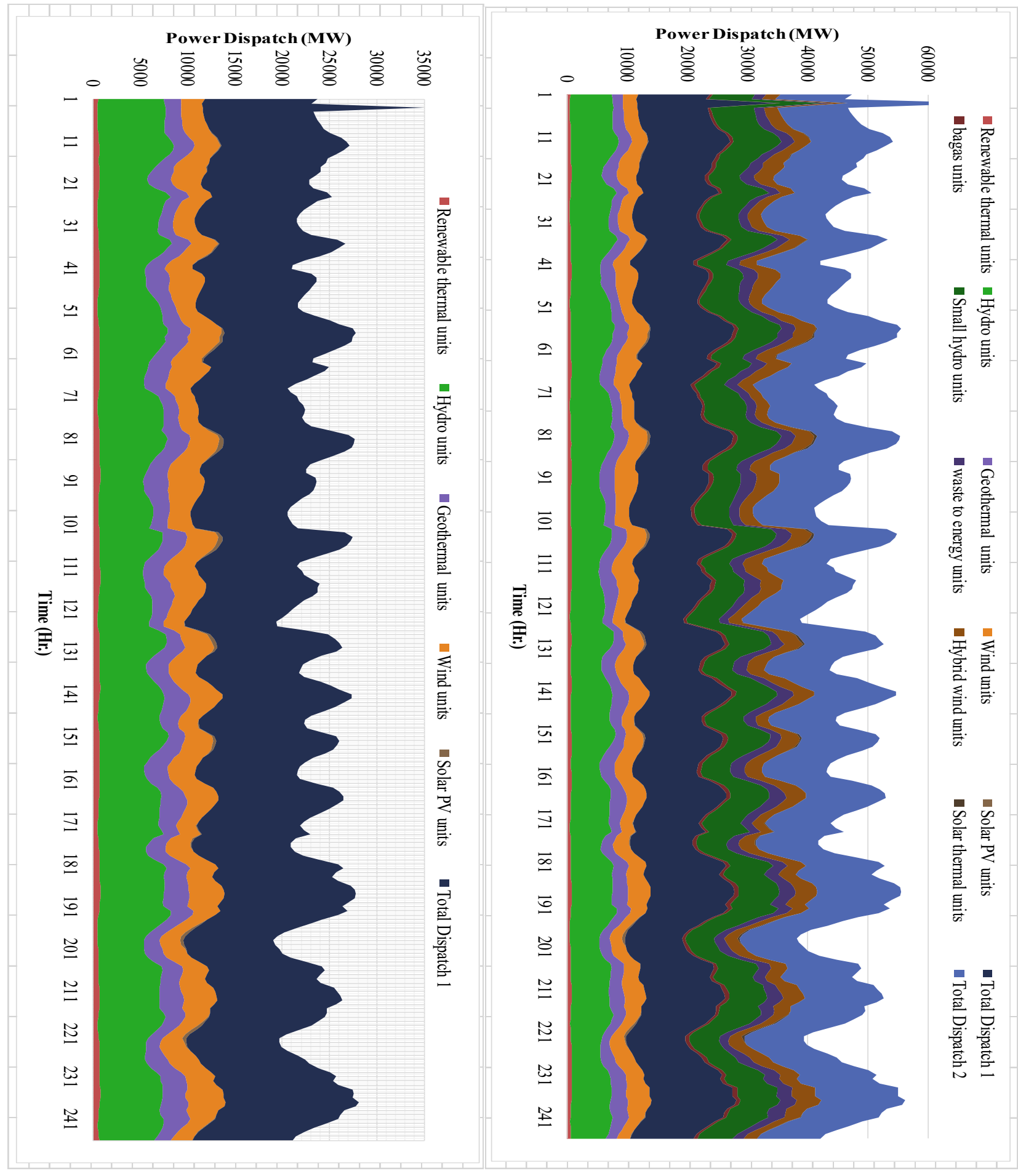

Figure 13. Weekly dispatch Ethiopian Renewable Energy System

The composition of the load is a bit different from the state cities' commercial and public services as large infrastructure, industries, schools, and hospitals operate mainly between 8:00 Am and 6:00 Pm. Additionally, the country's suburbs can largely consist of small shops, hotels, bars, cafes, and restaurants that stay open throughout the evening. Available data is used to understand OGD and the dispatch contribution of each generating unit.
Figures 11, 12 and 13 depict the energy share and dispatch of each Ethiopian generating unit committed so far to supply $10.023 \mathrm{GW}$ of power. A comparison between different solution methods of economic dispatch for a 3 unit renewable generation is presented in Table 1. The execution time and production cost of the system solved using GA-HNN is less than that of conventional methods. This comparison was done to indicate the robustness of GA-HNN. 
Table 1. Multi-variable multi-objective simulation comparisons of HNN, EPGA, and GA-HNN

\begin{tabular}{|c|c|c|c|}
\hline Time & HNN Solution & EPGA Solution & GA-HNN Solution \\
\hline 1 & $\sqrt{11847.04}$ & 11847.04155 & 11850.04155 \\
\hline 2 & 11547.13 & 11547.12606 & 11550.12606 \\
\hline 3 & 23394.17 & ล 23394.16761 & 23395.16761 \\
\hline 4 & 11662.13 & (11662.1314 & 11665.1314 \\
\hline 5 & 11768.15 & H 11768.15114 & 11770.15114 \\
\hline 8 & 11866.71 & 11866.71086 & 11865.71086 \\
\hline 7 & b 12034.89 & 12034.88594 & 12035.88594 \\
\hline 8 & b 12219.79 & 12219.79114 & 12220.79114 \\
\hline 9 & b 12543.93 & 12543.93396 & 12545.93396 \\
\hline 10 & 13130.48 & 13130.47914 & 13130.47914 \\
\hline 11 & 13397.93 & 13397.92534 & 13400.92534 \\
\hline 12 & 13540.31 & 13540.30971 & 13540.30971 \\
\hline 13 & 13260.92 & 13260.92285 & 13260.92285 \\
\hline 14 & b 12859.55 & 12859.55294 & 12860.55294 \\
\hline 15 & 12431.65 & 12431.65383 & 12435.65383 \\
\hline 16 & 12312.82 & 12312.81593 & 12315.81593 \\
\hline 17 & 12017.45 & 12017.45115 & 12017.45115 \\
\hline 18 & 12041.08 & 12041.07891 & 12045.07891 \\
\hline 19 & 11757.06 & 11757.05716 & 11760.05716 \\
\hline 20 & 11453.42 & 11453.41733 & 11455.41733 \\
\hline 21 & 11424.6 & (11424.6024 & 11425.6024 \\
\hline 22 & 11654.52 & 11654.52416 & 11655.52416 \\
\hline 23 & 12368.03 & 12368.02728 & 12370.02728 \\
\hline 24 & $\sqrt{12642.14}$ & 12642.14203 & 12645.14203 \\
\hline $\operatorname{Pm}(\mathrm{MW})$ & $3.22315 \mathrm{E}-05$ & $3.16214 \mathrm{E}-05$ & $2.85323 \mathrm{E}-06$ \\
\hline P loss (MW) & 36.78 & 36.23 & 35.23 \\
\hline $\operatorname{Cost}(\$ / M W)$ & $520,614.85$ & $520,001.24$ & $519,971.00$ \\
\hline Run time (sec) & 0.6875 & 0.2692 & 0.12812 \\
\hline
\end{tabular}

\section{Conclusions}

This paper presents an optimal generation dispatch of Ethiopian power systems using the hybrid Genetic Algorithm-Hopfield neural network (GA-HNN) approach. Reformulation of generation dispatch for Ethiopian power system comprising biomass, large and micro-hydro plants, solar PV, solar thermal, waste to energy plant, wind farm, and geothermal is presented. Each of these sources requires problem formulation and constraint handling mechanisms considering security limits and credible contingencies. This enables renewable energy fuelled power systems to provide secure and reliable service. The Ethiopian power system was used as case study. Modelling and simulation were conducted on MATLAB simulation platform.

According to the simulation results obtained, it can be deduced that GA-HNN based optimal dispatch of Ethiopian power system is a promising step in connection to developments needed in the adoption and realization of smarter grids as it is an excellent solution method of anticipating intermittent fluctuating and predictive control.
Employing optimal generation dispatch using a hybrid Hopfield neural network-genetic algorithm approach for intermittent renewables concurrently increases their security level and decreases total generation cost. It is also worth noticing solving OGD using GA-HN provides optimal allocation of generation level, contingency reserve and penalty reserves that help power system operation regain normal operation after blackout occur. Generally, limiting the number of recursive blackouts, reducing generation cost, allocating optimal generation level and reducing computation time are prospects of GAHNN based OGD.

\section{References}

[1] M. A. Tikuneh and G. B. Worku, "Identification of system vulnerabilities in the Ethiopian electric power system," Glob. Energy Interconnect., vol. 1, no. 3, pp. 358-365, 2018.

[2] Q. Lin, X. Shen, Y. Sun, Z. Li, Q. Guo, and H. Sun, “A Corrective Control Approach For Combined Heat And Power System integrated with Multiple Energy Storage System," 2019 IEEE PES Innov. Smart Grid Technol. Asia, ISGT 2019, no. 2018, pp. 1497-1502, 2019.

[3] O. Gandhi, C. D. Rodriguez-Gallegos, and D. Srinivasan, "Review of optimization of power dispatch in renewable energy system," IEEE PES Innov. Smart Grid Technol. Conf. Eur., pp. 250-257, 2016.

[4] W. Cheng and H. Zhang, "A dynamic economic dispatch model incorporating wind power based on chance constrained programming," Energies, vol. 8, no. 1, pp. 233-256, 2015.

[5] I. C. Hirth, Lion, "The Economics of Wind \& Solar Variability - How the Variability of Wind and Solar Power affect their Marginal Value, Optimal Deployment, and Integration Cost," no. November, pp. 1-213, 2014.

[6] A. Santhosh, A. M. Farid, and K. Youcef-Toumi, "Real-time economic dispatch for the supply side of the energywater nexus," Appl. Energy, vol. 122, pp. 42-52, 2014.

[7] X. Jin et al., "Security-Constrained Economic Dispatch for Integrated Natural Gas and Electricity Systems," Energy Procedia, vol. 88, pp. 330-335, 2016.

[8] K. Jihane and M. Cherkaoui, "Economic dispatch optimization for system integrating renewable energy sources," AIP Conf. Proc., vol. 1968, 2018.

[9] A. A. Demissie and A. A. Solomon, "Power system sensitivity to extreme hydrological conditions as studied using an integrated reservoir and power system dispatch model, the case of Ethiopia," Appl. Energy, vol. 182, pp. 442-463, 2016.

[10] Q. Wang, "Risk-based security-constrained optimal power flow: Mathematical fundamentals, computational strategies, validation, and use within electricity markets by Qin Wang A dissertation submitted to the graduate faculty in partial fulfillment of the requirem," 2013.

[11] S. Brini, A. H. H, and A. Ouali, "Economic Dispatch for Power System Included Wind and Solar Thermal Energy," Leonardo J. Sci., vol. 8, no. 14, pp. 204-220, 2009. 
[12] S. Tsegaye and F. Shewarega, "Recent-Trends-onSecurity-Constrained-Economic-Dispatch-ABibliographic-Review," World Acad. Sci. Eng. Technol. Int. J. Electr. Comput. Eng., vol. 13, no. 7, pp. 466471, 2019.

[13] A. Gupta, R. P. Saini, and M. P. Sharma, "Modelling of hybrid energy system-Part I: Problem formulation and model development," Renew. Energy, vol. 36, no. 2, pp. 459-465, 2011.

[14] S. R. Moreno and E. Kaviski, "Daily Scheduling of Small Hydro Power Plants Dispatch With Modified Particles Swarm Optimization," Pesqui. Operacional, vol. 35, no. 1, pp. 25-37, 2015.

[15] E. M. Natsheh, "Hybrid Power Systems Energy Management Based on Artificial Intelligence," PHD Thesis, vol. PHD Thesis, no. July, 2013.

[16] N. Gupta, G. S. Gaba, H. Singh, and G. International, “A New Approach for Function Optimization using Hybrid GA- ANN Algorithm Gurjot Singh Gaba Harsimranjit Singh Gill," vol. 2, no. 2, pp. 386-389, 2012.

[17] B. G. Tsegaye S., Shewarega F., "Security Constrained Economic Dispatch of Renewable Energy Systems.," in International Conference on Advances of Science and Technology, ICAST 2020, 2021, pp. 361-375.

[18] M. Javadi, T. Amraee, and F. Capitanescu, "Look ahead dynamic security-constrained economic dispatch considering frequency stability and smart loads," Int. J. Electr. Power Energy Syst., vol. 108, no. January, pp. 240-251, 2019.

[19] K. Teeparthi and D. M. Vinod Kumar, "Multi-objective hybrid PSO-APO algorithm based security constrained optimal power flow with wind and thermal generators," Eng. Sci. Technol. an Int. J., vol. 20, no. 2, pp. 411426, 2017.

[20] V. Sarfi and H. Livani, "An economic-reliability securityconstrained optimal dispatch for microgrids," IEEE Trans. Power Syst., vol. 33, no. 6, pp. 6777-6786, 2018.

[21] D. Zhu and G. Hug-Glanzmann, "Decomposition methods for stochastic optimal coordination of energy storage and generation," IEEE Power Energy Soc. Gen. Meet., vol. 2014-Octob, no. October, pp. 1-5, 2014.

[22] S. K. Damodaran and T. K. S. Kumar, "Hydro-thermalwind generation scheduling considering economic and environmental factors using heuristic algorithms," Energies, vol. 11, no. 2, 2018.

[23] A. A. ElDesouky, "Security and stochastic economic dispatch of power system including wind and solar resources with environmental consideration," Int. J. Renew. Energy Res., vol. 3, no. 4, pp. 951-958, 2013

[24] P. P. Biswas, P. N. Suganthan, B. Y. Qu, and G. A. J. Amaratunga, "Multiobjective economic-environmental power dispatch with stochastic wind-solar-small hydro power," Energy, vol. 150, no. April, pp. 1039-1057, 2018.

[25] A. A. ElDesouky, "Security and Stochastic Economic Dispatch of Power System Including Wind and Solar Resources with Environmental Consideration," Int. J. Renew. Energy Res., vol. 3, no. 4, pp. 951-958, 2013.

[26] E. T. H. No, D. O. F. Sciences, E. T. H. Zurich, and E. T. H. Zurich, "ii c 2013 Maria Vrakopoulou All Rights Reserved," vol. 6, no. 237.

[27] S. Tsegaye, F. Shewarega, and G. Bekele, "A Review on Security Constrained Economic Dispatch of Integrated Renewable Energy Systems," EAI Endorsed Trans. Energy Web, 2020.

[28] T. Yalcinoz, H. Altun, and M. Uzam, "Algorithm Based on Arithmetic Crossover," Power, 2001.

[29] P. Roy and A. Chakrabarti, "Modified Shuffled Frog Leaping Algorithm for Solving Economic Load Dispatch Problem," Energy Power Eng., vol. 03, no. 04, pp. 551-556, 2011.

[30] S. Tsegaye, F. Shewarega, and G. Bekele, "Hopfield Neural Network-based Security Constrained Economic Dispatch of Renewable Energy Systems," EAI Endorsed Trans. Energy Web Online First, 2021.

[31] T. Yalcinoz, B. J. Cory, and M. J. Short, "Hopfield neural network approaches to economic dispatch problems," Int. J. Electr. Power Energy Syst., vol. 23, no. 6, pp. 435-442, 2001.

[32] S. Salcedo-Sanz and X. Yao, "A hybrid Hopfield networkgenetic algorithm approach for the terminal assignment problem," IEEE Trans. Syst. Man, Cybern. Part B Cybern., vol. 34, no. 6, pp. 2343-2353, 2004.

[33] Z. Jia-qing, "Research on Environmental Economic Dispatch of Power System Including Wind Farm," Phys. Procedia, vol. 24, pp. 107-113, 2012.

[34] M. J. Ali, N. J. B, M. Rehman, M. U. Sharif, and M. K. Khan, "State Based Load Balancing Algorithm for Smart Grid Energy Management in," vol. 8, no. May, pp. 220-232, 2018.

[35] S. Frank, I. Steponavice, and S. Rebennack, "Optimal Power Flow : A Bibliographic Survey I Formulations and Deterministic Methods." 